\title{
Evaluation of sensitivity and spesitivity as COVID-19 screening method
}

\author{
Atikah Nurhesti $^{1}$, Solikhah Solikhah ${ }^{2}$, Sitti Nur Djannah ${ }^{3}$ \\ ${ }^{1}$ Sleman Health Office, Sleman Regency Office, Indonesia \\ ${ }^{1,2,3}$ Department of Public Health, Faculty of Public Health, Universitas Ahmad Dahlan, Yogyakarta, Indonesia
}

\begin{abstract}
Article Info
ABSTRACT

\section{Article history:}

Received Mar 1, 2021

Revised Aug 16, 2021

Accepted Aug 25, 2021

\section{Keywords:}

Antibody rapid tes

COVID-19

Screening

Sensitivity

Specificity

Coronavirus disease 2019 (COVID-19) is caused by the severe acute respiratory syndrome coronavirus 2 (SARS-CoV-2). Antibody rapid test is one of the COVID-19 screening tests that can be used in the community. The accuracy of the rapid antibody methods needs to be appropriately assessed, it is necessary to carry out a diagnostic accuracy study using a pairwise sensitivity and specificity analysis. This research aimed to assess the sensitivity and specificity of COVID-19 rapid tests, also assesses positive predictive value (PPV) and negative predictive value (NPV) of the rapid antibody test as a method of screening for COVID-19 in Sleman Regency, Indonesia. In total, 118 respondents who have contact with COVID-19 patients and have symptoms were enrolled in this study. The study was conducted on 118 patients who had been in contact with confirmed COVID19118 patients who met the close contact criteria were conducted a rapid antibody test. $64.41 \%$ patients were reactive. Real-time polymerase chain reaction (RT PCR) as a gold standard was also carried out for all patients and $63.56 \%$ affirmed positive for COVID-19. The sensitivity value was $97.33 \%$, and the specificity value was $93.02 \%$, while the positive predictive value (NPP) was $96.05 \%$, and the negative predictive value (NPN) was $95.24 \%$. These results meet the minimum recommendations for the screening method.
\end{abstract}

This is an open access article under the $\underline{C C B Y-S A}$ license.

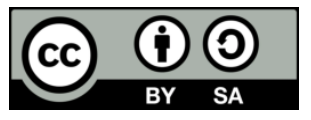

Corresponding Author:

Atikah Nurhesti

Sleman Health Office

Sleman Regency Office, Indonesia

Email: atikahnurhesti@gmail.com

\section{INTRODUCTION}

Coronavirus disease (COVID-19) is caused by the severe acute respiratory syndrome coronavirus 2 (SARS-CoV-2). SARS-CoV-2 transmission occurs from symptomatic patients through droplets that come out when coughing or sneezing. Meanwhile, cases related to transmission from asymptomatic patients generally have a history of close contact with COVID-19 patients [1]. The first cases of COVID-19 were reported in Indonesia on March 2, 2020, totaling two cases. Data shows that there are 1,528 confirmed cases and 136 deaths in March 2020 [2]. Meanwhile, the COVID-19 case in Sleman Regency, Indonesia was first recorded on March 18, 2020. Based on data from the Sleman Regency Health Service, on July 31, 2020, there were 233 cases, with eight of them dying, so the mortality rate reached $3.43 \%$ [3].

The fact that the entire world has been exposed to COVID-19 is causing the economy to disrupt. Therefore to re-open economic activity, health care encourages antibody tests for screening COVID-19 in the community [4]. The rapid test is use as a choice because it can detect immunoglobulin $\mathrm{M}$ ( $\operatorname{IgM}$ ) as a form of the body's defense response against viral infections. It also detects Immunoglobulin $\mathrm{G}$ (IgG), which is an immunological and immune memory. The process of forming $\mathrm{IgG}$ and $\mathrm{IgM}$ antibodies as a result of infection 
with SARS COV-2 that causes COVID-19 is an essential indication in this test [5]. In America, people are scrambling to carry out rapid antibody tests to escape lockdown [6]. But this strategy means nothing if the test result can't be trusted [6] therefore, the accuracy of antibody test is essential. Currently, the US Food and Drug Administration have given commercial test manufacturers authorization for COVID-19 antibody test. Sensitivity and specificity are required before their use in clinical practice [4].

The process of forming IgG and IgM antibodies as a result of infection with SARS COV-2 that causes COVID-19 is an important indication in this test [5]. In general, IgM is produced earlier, followed by IgG production. However, studies of SARS COV-2 have shown that IgM and IgG development often occur at the same time [7]. Most of the cases obtained do not show clinical manifestations or asymptomatic. Therefore, the rapid antibody test is expected to have a high sensitivity and specificity level so that the examination results are accurate. The accuracy of the rapid antibody methods needs to be appropriately assessed. Sensitivity for instance depends on the method itself [8] and the timing exposure and onset of symptoms [9]. To evaluate the rapid test method, it is necessary to carry out a diagnostic accuracy study using a pairwise sensitivity and specificity analysis [10]. Sensitivity can describe the probability of measuring the likelihood for a rapid test to pick up the presence of disease; alternatively, a true positive is recorded when a procedure reflects the presence of the pathogen in a contaminated sample. Meanwhile, Furthermore, we define specificity as the probability of measuring the likelihood for a test to pick up the absence of a disease/pathogen, alternatively, a true negative is recorded when a procedure reflects the absence of a pathogen when the sample is not contaminated [11]-[13]. False-negative result may cause COVID-19 transmission in community, false-positif may impact with patient psychological condition, and patient may suffer from quarantined at home.

The CDC recommends three approaches for choosing and optimizing antibody tests. First, a population with more than 5\% prevalence of COVID-19 and should choose an antibody test with high specifity [4]. Second antibody test use for any person who previously was exposed to COVID-19 and encourage patient with positive for COVID-19 to be tested with antibody test [16]. Sleman District Health-Office effort to screen for COVID-19 in the community uses the IgM and IgG Rapid Test or antibody rapid test. One study revealed that the rapid test is the right choice because it is easier to use for COVID-19 screening in the community. The prevalence of COVID-19 cases in Sleman is 8.9\%, and one-off screening policy in Sleman is close contact cases and suspected are given antibody tests. The Centers for Disease Control (CDC) recommend that rapid antibodies be used in areas with a prevalence of more than 5\% and given to people who have had contact with or have been exposed to COVID-19. Therefore, the researchers intend to assess the sensitivity and specificity of the antibody Rapid Test as a method of screening for COVID-19 in the Sleman Regency.

\section{RESEARCH METHOD}

The respondents of this study were 118 people of Sleman Regency, Indonesia who received a rapid test antibody and met the inclusion and exclusion criteria. The inclusion criteria are: i) residents in the Sleman Regency; ii) receive a rapid antibody test by the Health Office of Sleman Regency; iii) conducted on people who meet the criteria for close contact/suspect/COVID-19; iv) the rapid test kit used is in the list of recommendations government. The primary objective of this study was to assess the sensitivity, specificity, and predictive value of the antibody test. Data were analyzed using univariate analysis, then further analysis was carried out on the test results for IgM and IgG based on the results of the sensitivity and specificity calculations. Furthermore, an analysis is followed based on the results of the estimate of positive predictive value and negative predictive value. The protocol of this study was approved by the ethics commission of Ahmad Dahlan University, Yogyakarta, Indonesia number Skep/041/KEP/VI/2020

\section{RESULTS AND DISCUSSION}

\subsection{Result}

The study was carried out in August 2020. The study was conducted on 118 patients who had been in contact with confirmed COVID 19. $91.5 \%$ of the 118 patients experienced various symptoms, a rapid test was carried out on all patient and the results showed that $64.41 \%$ were reactive. Real-time polymerase chain reaction (RT PCR) was carried out for all patients for diagnosis with $63.56 \%$ confirmed positive for COVID19. The 118 samples were analyzed consist of $100 \%$ female samples $59.32 \%$ of the respondents' age is $>15$ years old and $90.68 \%$ respondent's work status is not working. The result of antibody test and medical record patient were reviewed to conclude. Characteristics of the respondents can be seen in Table 1. The results of antibody tests conducted on respondents were as many as $76(64.41 \%)$ people showing reactive results. Meanwhile in Table 2 shows the result of the RT PCR examination the results were $75(63.56 \%)$ positive and 43 negatives $(35.59 \%)$. 
Table 1. Characteristics of respondents, symptoms, and antibody rapid test results

\begin{tabular}{|c|c|c|c|c|c|c|}
\hline \multirow{2}{*}{$\begin{array}{l}\text { Characteristics } \\
\text { Age }\end{array}$} & \multicolumn{6}{|c|}{ Symptoms of COVID-19 experienced } \\
\hline & Asymptomatic & 1 symptom & 2 symptoms & 3 symptoms & $>3$ symptoms & Total \\
\hline$\leq 15$ years & 0 & 17 & 24 & 7 & 1 & $49(41.53 \%)$ \\
\hline$>15$ years & 10 & 9 & 24 & 13 & 13 & $69(58.47 \%)$ \\
\hline \multicolumn{7}{|l|}{ Gender } \\
\hline Man & 0 & 0 & 0 & 0 & 0 & $0(0 \%)$ \\
\hline Woman & 10 & 26 & 48 & 20 & 14 & $118(100 \%)$ \\
\hline \multicolumn{7}{|l|}{ Employment } \\
\hline Unemployed & 0 & 25 & 48 & 20 & 14 & $107(90.68 \%)$ \\
\hline Employed & 10 & 1 & 0 & 0 & 0 & $11(9.32 \%)$ \\
\hline \multicolumn{7}{|l|}{ Rapid test results } \\
\hline Reactive & 2 & 12 & 33 & 15 & 14 & $76(64.41 \%)$ \\
\hline Non reactive & 8 & 14 & 15 & 5 & 0 & $42(35.59 \%)$ \\
\hline
\end{tabular}

Table 2. The results of the rapid antibody test and RT PCR test

\begin{tabular}{lcc}
\hline \multicolumn{1}{c}{ Check up result } & Total & Percentage \\
\hline Antibody rapid test & & \\
Reactive & 76 & 64.41 \\
Non-reactive & 42 & 35.59 \\
Total & 118 & 100 \\
RT PCR test & & \\
Negative & 43 & 36.44 \\
Positive & 75 & 63.56 \\
Total & 118 & 100 \\
\hline
\end{tabular}

Furthermore, an assessment of all medical record samples with symptoms was carried out. Table 3 shows that the symptoms experienced by most of the respondents were not being able to smell as many as 75 people $(63.56 \%)$. While the least symptoms experienced by respondents included bitter tongue, difficulty defecating, headaches, and earaches, each experienced by one person $(0.85 \%)$. Based on the data that has been collected, the calculation of sensitivity, specificity, and predictive value is then performed. The results of data processing are summarized in Table 4. The results are sensitivity value was $97.33 \%$ and the specificity value was $93.02 \%$, while the positive predictive value (NPP) was $96.05 \%$ and the negative predictive value (NPN) was $95.24 \%$.

Table 3. Frequency distribution of antibody rapid test results based on symptoms experienced

\begin{tabular}{ccc}
\hline Symptoms experienced & \multicolumn{2}{c}{ Frequency } \\
\hline Can not smell & $75(63.56 \%)$ & $43(36.44 \%)$ \\
Could not tell the taste & $55(46.61 \%)$ & $63(53.39 \%)$ \\
Cold & $26(22.03 \%)$ & $92(77.97 \%)$ \\
Cough & $32(27.12)$ & $86(72.88 \%)$ \\
Red eye & $3(2.54 \%)$ & $115(97.46 \%)$ \\
Bitter tongue & $1(0.85 \%)$ & $117(99.15 \%)$ \\
Fever & $14(11.86 \%)$ & $104(88.14 \%)$ \\
Migraine & $3(2.54 \%)$ & $115(97.46 \%)$ \\
Dizzy & $17(14.41 \%)$ & $101(85.59 \%)$ \\
Nose sore/sore & $2(1.69 \%)$ & $116(98.31 \%)$ \\
Sore throat & $3(2.54 \%)$ & $115(97.46 \%)$ \\
Difficult to defecate & $1(0.85 \%)$ & $117(99.15 \%)$ \\
Headache & $1(0.85 \%)$ & $117(99.15 \%)$ \\
Inflammation & $3(2.54 \%)$ & $115(97.46 \%)$ \\
Ear pain & $1(0.85 \%)$ & $117(99.15 \%)$ \\
Nosebleed & $2(1.69 \%)$ & $116(98.31 \%)$ \\
Chest tightness/shortness of breath & $3(2.54 \%)$ & $115(97.46 \%)$ \\
\hline
\end{tabular}

Table 4. Sensitivity and specificity of antibody rapid test

\begin{tabular}{|c|c|c|c|c|c|c|c|}
\hline \multirow{2}{*}{$\begin{array}{l}\text { Results of the screening } \\
\text { (rapid antibody test) }\end{array}$} & \multicolumn{2}{|c|}{ RT PCR results } & \multirow{2}{*}{ Total } & \multirow{2}{*}{$\begin{array}{c}\text { Sensitivity } \\
(\%)\end{array}$} & \multirow{2}{*}{$\begin{array}{l}\text { Specificity } \\
(\%)\end{array}$} & \multirow{2}{*}{$\begin{array}{c}\text { Positive } \\
\text { predicted value }\end{array}$} & \multirow{2}{*}{$\begin{array}{c}\text { Negative } \\
\text { predicted value }\end{array}$} \\
\hline & Positive & Negative & & & & & \\
\hline Reactive & 73 & 3 & 76 & & & & \\
\hline Non-reactive & 2 & 40 & 42 & 97.33 & 93.02 & 96.05 & 95.24 \\
\hline Total & 75 & 43 & 118 & & & & \\
\hline
\end{tabular}


Ability of the rapid test assessment is carried out using the area under the curve (AUC). The wider the AUC, the better the ability of a test to detect a disease. The ability of a test is declared well if AUC $\geq 0.7$. The result is 0.1968 this means that the ability of the rapid test antibody is good for detecting COVID-19. The AUC rapid test is shown in Figure 1.

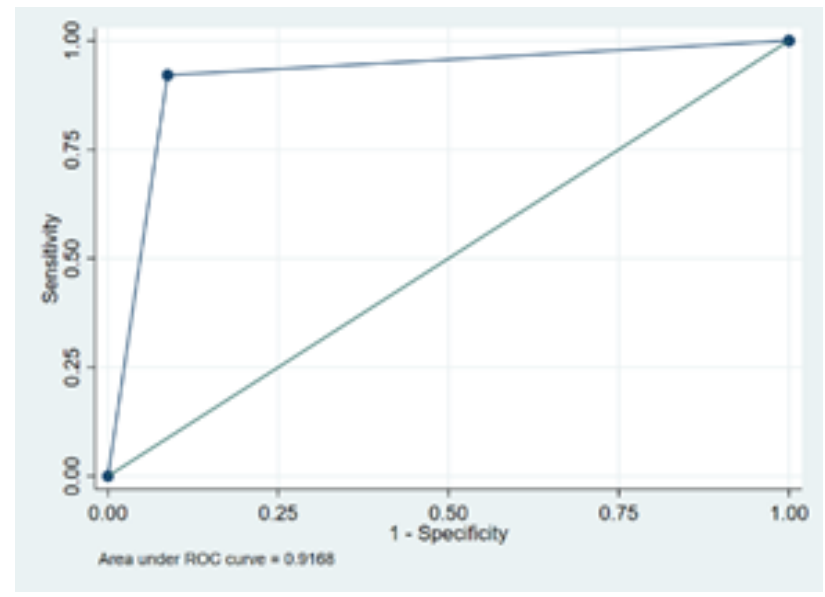

Figure 1. The AUC

\subsection{Discussion}

In this study we evaluated rapid test for screening of COVID-19 in Sleman Regency. Samples from COVID-19 cases obtained during April 2020 who's qualify as close contact and confirmed by PCR were use as gold standar. The 55 people $(75.33 \%)$ with symptom are $>15$ years old, these results are the same as the findings of a study in Beijing where the majority of young adults were $77 \%$ [1].

Clinical manifestations of COVID-19 cases include no symptoms (asymptomatic), mild symptoms, pneumonia, severe pneumonia, Acute Respiratory Disorder Syndrome, sepsis, and septic shock. About 80\% of cases were classified as mild or moderate, $13.8 \%$ were seriously ill and as many as $6.1 \%$ of patients fell into a critical condition. Most patients infected with SARS-CoV-2 show symptoms in the respiratory system such as fever, coughing, sneezing, and shortness of breath [17]. Based on follow-up examinations using the RT PCR method, 75 people $(63.56 \%)$ were positive for COVID-19.

The screening was carried out using the rapid test method. In order to know the validity of the results, it is necessary to assess the sensitivity and specificity. The current study suggested sensitivity and specificity test for the rapid test tool are $88.66 \%$ and a specificity of 90.63 for IgM and IgG [5]. These two parameters' values were determined using a diagnostic tool that meets the gold standard, namely RT PCR. These two values influence each other. If the sensitivity value increases, the specificity will decrease and vice versa. Based on the calculation results, the sensitivity of the rapid test to the RT PCR results reached $97.33 \%$, and the specificity was $93.02 \%$. The sensitivity of the rapid test resulted in a figure of $97.33 \%$ indicating the ability of the test kit to predict a patient with COVID-19, while the specificity of the rapid test resulted in a figure of $93.02 \%$ which means that it is good at predicting a patient is not sick with COVID-19. The sensitivity and specificity of an antibody test will vary in results depending on several factors.

Meta-data research conducted in Brazil on 16 rapid test products resulted in a sensitivity and specificity of $82 \%$ and $97 \%$ [19]. While the results of research conducted in Austria found that the sensitivity and specificity were $98 \%$ and $97 \%$ [20]. A study conducted in France on 34 positive patients with COVID-19 using three different antibody tests found that all three antibody tests had a sensitivity of around $80 \%$ [21]. A study conducted in Germany on 26 samples using four kinds of rapid tests found that the sensitivity ranged from $92.3 \%$ - 100\% while the specificity ranged from $84 \%-100 \%$ [22]. Research conducted in Finland with 70 samples from COVID patients and 81 control samples found that the sensitivity ranged from $68.3 \%$ $97.5 \%$ and specificities between $43.8 \%-81.3 \%$ [23]. In Italy, the research was conducted on samples with several times taking, namely seven days, 14 days, and $>14$ days, the resulting sensitivity was $58.3 \%, 85.79 \%$, and $100 \%$ [24]. Research in Spain on three kinds of rapid test antibodies found sensitivity and specificity values were $100 \%$ and $80.6 \%$ [25]. A study conducted in China of 150 patients stated that the rapid test antibody has a sensitivity of $71.1 \%$ and a specificity of $96.2 \%$ [26].

To know the predictive validity, it is known by the positive predictive value (PPV) and the Negative Predictive Value (NPV). PPV is a possible subject that is positively identified by the test equipment 
according to the gold standard. PPV in the screening tool represents the proportion of subjects classified as ill will have a disease in the future [9]. Based on the calculation, the PPV is $96.05 \%$, which means that the proportion of predictions of patients who test positive and will suffer from illness. The use of rapid tests for screening with high sensitivity and PPV values can increase public confidence. However, the predictive value (both PPV and NPV) in the study can not be applied in the population because of differences in the prevalence of cases that occur [9].

There are many rapid antibody test product developments and markets [18], [10]-[30]. Some of these have been evaluated in studies conducted in other countries. However, the sensitivity and specificity values cannot be used as benchmarks in assessing the accuracy of rapid antibody results, but also need to take into account the onset of symptoms and detection of antibodies inhibits sensitivity [24], [31]. Detection of IgG, IgM, and IgA antibodies against SARS-CoV-2 cannot be used as a diagnosis of COVID-19 but as a complement to the RT PCR test in assessing an individual's immune status [24].

This study has several limitations, first: there is no standard for determining the minimum sample size in assessing the sensitivity and specificity of the rapid tests used for screening. Second, no reliable gold standard for serologic assays is currently available for comparative studies, and little literature exists regarding the comparison of the rapid test method for detection of COVIC-19. Furthermore, the criteria for assessing the time of disease onset are taken from the last time sample contact with a positive case and may contain imprecision due to subjectivity in the perception of symptoms and timing.

\section{CONCLUSION}

The sensitivity value of the rapid test antibody used in the study was $97.33 \%$ indicating the ability of the test kit to predict a patient with COVID-19. The specific value of the antibody rapid test used in the study was $93.02 \%$, indicating that individuals who are not sick with COVID-19. The positive predictive value (NPP) of antibody rapid test used in the study was $96.05 \%$. The negative predictive value (NPN) of the antibody rapid test used in the study was $95.24 \%$. These results meet the minimum recommendations for the screening method.

\section{ACKNOWLEDGEMENTS}

We thank all health-care workers involved in the screening, diagnosis, and treatment of COVID-19 patients in the primary health care, hospital in Sleman Regency, and also Sleman Health Office team.

\section{REFERENCES}

[1] S. Tian et al., "Characteristics of COVID-19 infection in Beijing," J. Infect., vol. 80, no. 4, pp. 401-406, 2020, doi: 10.1016/j.jinf.2020.02.018.

[2] Y. Yarmaliza et al., "Literature Review of Epidemiological Phenomena: Corona Virus Disease Pandemic 2019," Eur. J. Med. Heal. Sci., vol. 2, no. 3, pp. 1-6, 2020, doi: 10.24018/ejmed.2020.2.3.281.

[3] Sleman District Health Office, "Dashboard Informasi COVID-19 Kabupaten Sleman," 2020, [Online]. Available: https://covidtracer.slemankab.go.id/dashboard2/.

[4] J. Kopel, H. Goyal, and A. Perisetti, "Antibody Tests for Auto Antibody," Baylor Univ Med Cent Proc., vol. 34, no. 1, pp. 63-72, 2020.

[5] Z. Li et al., "Development and clinical application of a rapid IgM-IgG combined antibody test for SARS-CoV-2 infection diagnosis," J Med Virol., vol. 92, no. 9, pp. 1518-1524, 2020, doi: 10.1002/jmv.25727.

[6] A. Mandavilli, "Coronavirus Antibody Tests: Can You Trust the Results? The New York Times, 2020, [Online]. Available: https://www.nytimes.com/2020/04/24/health/coronavirus-antibody-tests.html. Published 2020.

[7] T. Hoffman et al., "Evaluation of a COVID-19 IgM and IgG rapid test; an efficient tool for assessment of past exposure to SARS-CoV-2," Infect Ecol Epidemiol., vol. 10, no. 1, pp. 1-5, 2020, doi: 10.1080/20008686.2020.1754538.

[8] Z. Bisoffi et al., "Sensitivity, Specificity and Predictive Values of Molecular and Serological Tests for COVID-19," Epidemiol Prev, vol. 44, no. 2-3, pp. 189-190, 2020, doi: 10.19191/EP20.2-3.P189.042.

[9] NJ. Beeching and TE. Fletcher, "COVID-19 : testing times," BMJ, vol. 396, no. 1403, doi: 10.1136/bmj.m1403.

[10] JB. Reitsma, AS. Glas, AWS. Rutjes, RJPM. Bossuyt, and P. M Zwinderman AH., "Bivariate analysis of sensitivity and specificity produces informative summary measures in diagnostic reviews," Journal of Clinical Epidemiology, vol. 58, no. 10, pp. 982-990, 2005, doi: 10.1016/j.jclinepi.2005.02.022.

[11] Owusu-Ansah E de-GJ, A. Sampson, AK. Samuel, and A. Robert, "Sensitivity and Specificity Analysis Relation to Statistical Hypothesis Testing and Its Errors: Application to Cryptosporidium Detection Techniques," Open J Appl Sci., vol. 06, no. 04, pp. 209-216, 2016, doi: 10.4236/ojapps.2016.64022.

[12] F. Ye, S. Xu, Z. Rong, R. Xu, X. Liu, and P. Deng, "Delivery of infection from asymptomatic carriers of COVID19 in a familial cluster," Int J Infect Dis., vol. 94, pp. 133-138, 2020, doi: 10.1016/j.ijid.2020.03.042. 
[13] X. Meng, Y. Deng, Z. Dai, and Z. Meng, “COVID-19 and anosmia: A review based on up-to-date knowledge,” Am J Otolaryngol, vol. 41, no. 5, 2020, doi: 10.1016/j.amjoto.2020.102581.

[14] BE. Rachman, M. Rusli, and M. Miftahussurur, "The hidden vulnerability of COVID-19 observed from asymptomatic cases in Indonesia," Syst Rev Pharm., vol. 11, no. 2, pp. 703-713, 2020, doi: 10.31838/srp.2020.2.103.

[15] J. Xie et al., "Characteristics of Patients with Coronavirus Disease (COVID-19) Confirmed using an IgM-IgG Antibody Test," J Med Virol., vol. 92, no. 10, pp. 1-7, 2020, doi: 10.1002/jmv.25930.

[16] R. Castro, PM. Luz, MD. Wakimoto, VG. Veloso, B. Grinsztejn, and H. Perazzo, "COVID-19: A Meta-Analysis of Diagnostic Test Accuracy of Commercial Assays Registered in Brazil," Brazilian J Infect Dis., vol. 24, no. 2, pp. 180-187, 2020, doi: 10.1016/j.bjid.2020.04.003.

[17] C. Bundschuh et al., "Evaluation of the EDI enzyme linked immunosorbent assays for the detection of SARS-CoV2 IgM and IgG antibodies in human plasma," Clin Chim Acta., vol. 509, pp. 18-21, 2020, doi: 10.1016/j.cca.2020.05.049.

[18] T. Nicol et al., "Assesment of SARS-CoV-2 serological test for the diagnosis of COVID-19 through the evaluation of three immunoassays: two automated immunoassays (Euroimmun and Abbott) and one rapid lateral flow immunoassays (NG Biotech)," J Clin Virol., vol. 129, 2020, doi: 10.1016/j.jcv.2020.104511.

[19] V. Haselmann, M. Kittel, C. Gerhards, M. Thiaucourt, R. Eichner, V. Costina, and M. Neumaier, "Comparison of test performance of commercial anti-SARS-CoV-2 immunoassays in serum and plasma samples," Clin Chim Acta., vol. 510, pp. 73-78, 2020, doi: 10.1016/j.cca.2020.07.007.

[20] A. Jaaskelainen et al., "Performance of six SARS-CoV-2 immunoassays in comparison with microneutralisation," $J$ Clin Virol., vol. 129, 2020, doi: 10.1016/j.jcv.2020.104512.

[21] I. Montesinos, et al., "Evaluation of two automated and three rapid lateral flow immunoassays for detection of antiSARS-CoV-2 antibodies," J Clin Virol., vol. 128, 2020. doi: 10.1016/j.jcv.2020.104413.

[22] M. Serrano et al., "Comparasion of comercial lateral flow immunoassays and ELISA for SARS-CoV-2 antibody detection," J Clin Virol., vol. 129, 2020. doi:10.1016/j.jcv.2020.104529.

[23] B. Shen et al., "Clinical evaluationof a rapid coloidal gold immunochromatography assay for SARS-CoV-2 IgM/IgG," Am J Transl Res., vol. 12, no. 4, pp. 1348-1354, 2020.

[24] AK. Akobeng, "Understanding diagnostic tests 1: Sensitivity, specificity and predictive values," Acta Paediatr Int J Paediatr., vol. 96, no. 3, pp. 338-341, 2007, doi: 10.1111/j.1651-2227.2006.00180.x.

[25] H. Li et al., "A new and rapid approach for detecting COVID-19 based on S1 protein fragments," Clin Transl Med., vol. 10, no. 2, pp. 6-11, 2020, doi: 10.1002/ctm2.90.

[26] I. Cassaniti, "Performance of VivaDiag COVID-19 IgM/IgG Rapid Test is inadequate for diagnosis of COVID-19 in acute patients referring to emergency room department," J Med Virol. vol. 92, no. 10, pp. 1724-1727, 2020, doi: $10.1002 / j m v .25800$.

[27] WHO, "Advice on the Use of Point-of-Care Immunodiagnostic Tests for COVID-19 Rapid Diagnostic Tests Based on Antigen Detection," 2020, [Online]. Available: https://www.who.int/news-room/commentaries/detail/advice-onthe-use-of-point-of-care-immunodiagnostic-tests-for-covid-19.

[28] H. Fujigaki, "Reliability of serological tests for COVID-19: Comparison of three immunochromatography test kits for SARS-CoV-2 antibodies," Heliyon, vol. 6, no. 9, pp. 1-6, 2020, doi: 10.1016/j.heliyon.2020.e04929. 